
\title{
28 Research Square \\ Real-World Data Analysis of Healthcare Resource and Cost Utilization From Non-Alcoholic Fatty Liver Disease Patients in Japan
}

Ken Hasegawa ( $\sim$ kenhasegawa@fuji.waseda.jp )

Joint Graduate School of Tokyo Women's Medical University and Waseda University https://orcid.org/0000-0002-5941-3630

Atsushi Aruga

Tokyo Women's Medical University: Tokyo Joshi lka Daigaku

Original Article

Keywords: Non-alcoholic fatty liver disease, non-alcoholic steatohepatitis, hepatocellular carcinoma, liver cirrhosis, cost, database analysis, real-world, Japan

Posted Date: February 17th, 2021

DOl: https://doi.org/10.21203/rs.3.rs-201639/v1

License: (c) (i) This work is licensed under a Creative Commons Attribution 4.0 International License. Read Full License 


\section{Abstract}

Background: Demographic, healthcare resource utilization (HCRU), and healthcare costs of non-alcoholic fatty liver disease (NAFLD), non-alcoholic steatohepatitis (NASH) patients, and those progressed to liver cirrhosis (LC) and hepatocellular carcinoma (HCC) was assessed from Japan Medical Data Center (JMDC) claims database.

Methods: 185,012 NAFLD or NASH patients between $1^{\text {st }}$ January 2006 and $31^{\text {st }}$ July 2018 were identified from JMDC database. Mean annual all-cause HCRU and costs were reported pre- and post-index date of the initial diagnosis of NAFLD/NASH, LC and HCC. Age, gender, and comorbidity influence on post-index cost was assessed with a multivariable analysis.

Results: 123,379 NAFLD/NASH, 205 LC, and 96 HCC patients were selected into 3 liver severity cohorts based on the study inclusion/exclusion criteria. Majority of patients were male (70.0\% to $71.7 \%)$ with comorbid hyperlipidaemia (50.2\% to $61.5 \%$ ), diabetes mellitus ( $40.0 \%$ to $60.4 \%)$, and hypertension ( $27.9 \%$ to $42.7 \%)$ most prevalent across the 3 liver disease states. The mean all-cause healthcare annual cost significantly increased with liver disease severity, at $¥ 146,096$, $¥ 399,425$ and $¥ 842,875$ for NAFLD/NASH, LC and HCC patients, respectively. Comorbid cardiovascular disease (CVD), following by type 2 diabetes mellitus (T2DM) had the highest influence on all-cause cost with a cost ratio of 1.77 and 1.45 , respectively.

Conclusions: NAFLD/NASH patients with LC or HCC have increased comorbidity burden, high HCRU, and healthcare costs, which further highlights the importance and need of timely identification and management for NAFLD and NASH patients in Japan.

\section{Background}

Non-alcoholic fatty liver disease (NAFLD) is a disease burden rapidly growing and has become the most common cause of chronic liver disease globally [1]. Its histological spectrum starts from the simple steatosis and leads to the severe form of non-alcoholic steatohepatitis (NASH) in which hepatocellular damage and inflammation also exists besides steatosis [2]. The worldwide NAFLD prevalence is estimated at $25.2 \%$, and that of NASH between $1.5 \%$ and $6.5 \%[3,4]$. In Japan, increase of NAFLD has also been considered as a developing pandemic and its prevalence is estimated to be between the ranges of $30 \%$ and $35 \%$ [5-7], and the prevalence of NASH estimated between $1 \%$ and $9 \%$ [6].

NASH can further lead to fibrosis that results in liver cirrhosis (LC), hepatocellular carcinoma (HCC), as well as liver related mortality [8-10]. NASH patients is typically associated type 2 diabetes (T2DM), cardiovascular disease (CVD), and other metabolic disorders [11-13]. Currently there is no marketed product available for the treatment of $\mathrm{NASH}$, and most of the non-pharmacological treatments such as lifestyle modifications, and pharmacological treatments including insulin sensitizing agents, lipidlowering agents, and antioxidants are interventions recommended by clinical practice guidelines, but focused on managing the underlying disease rather than NASH itself [14-16]. 
NASH and its advanced liver forms are also linked to a significant economic burden, prompting research to quantify their associated costs. One study generated a Markov model approximating the annual healthcare cost burden linked to NAFLD in the United States (US), France, the United Kingdom, Italy, and Germany reporting the total burden was approximated to be $\$ 103$ billion ( $\$ 1,163 /$ patient) and $€ 35$ billion (between $€ 354$ and $€ 1163$ / patient) in the US and 4 European nations respectively [17]. Reports in other studies have displayed a high healthcare burden associated with NAFLD, especially for advanced liver diseases [18-20] nevertheless, information focusing on healthcare costs of NAFLD and NASH patients in Japan is limited. The objective of this analysis was to assess the real-world demographics, HCRU, and cost burden of NAFLD/NASH patients in Japan.

\section{Methods}

\section{Data source}

Data was retrieved from the Japan Medical Data Center (JMDC) claims database which includes the accumulated the recipients of outpatient, inpatient and pharmacy administrative claims data, composed approximately $4 \%$ of the total Japanese population from January 2005 [21]. The JMDC declares that the database contains data of de-identified organizational claims for the beneficiaries of health care insurance system of Kenpo that are employees of large-to-middle size firms in Japan as well as their dependents.

\section{NAFLD/NASH patient selection}

The JMDC database includes the standard disease code inputs that are Japan-specific and which are mapped to the International Classification of Disease Version 10 (ICD-10) codes [22]. In order to be eligible for this study, patients required at least one claim for NAFLD (standard disease code: 5718008, "hepatic steatosis", mapped to ICD-10 code: K76.0) or NASH (standard disease code: 8843497, "nonalcoholic steatohepatitis", mapped to ICD-10 code: K75.8) NAFLD between 1st January 2006 and 31st July 2018 inclusive. The index date was defined as the first day of the month of the patient's first visit for NAFLD or NASH, whichever came first. Eligible patients required to be $\geq 18$ years of age at index date, with minimum JMDC coverage of 12 months before index date (pre-index) and a minimum of 12 months after index date (post-index). Patients with any evidence of alcoholism, alcoholic liver disease or other causes of liver diseases were excluded from the analysis. Standard disease and ICD-10 codes to identify patient inclusion and exclusion are listed in Table S1 and Table S2 of the Supplementary Materials file respectively.

\section{Study cohorts}

Among the NAFLD/NASH cohort that progressed to LC or HCC during the study period, the initial diagnosis of LC or HCC was considered the new index date. Each LC or HCC cohort required a minimum of 12 months of follow-up post-index date. Table S1 of the Supplementary Materials file provides the standard disease and ICD-10 codes for each LC and HCC diagnosis. The 12 months before index date 
was considered the baseline pre-index period. The period between index date to end of JMDC coverage, end of the study period, 12 months post-index date, or the index date for the next disease state death, whichever was earliest was defined as the follow up period. The 12 months before index date was considered as the baseline pre-index period. All patients were followed for a variable post-index period defined as minimum of 12 months, until evidence of inpatient death, end of enrolment, progression to more severe stage, end of the study period, or end of 12 months, whichever was earliest. Claims databases do not capture comprehensive mortality information from all settings, hence only inpatient death could be considered here.

\section{Study outcomes}

Demographics and clinical characteristics were reported at the index date for each NAFLD/NASH, LC, and HCC. In addition, the body mass index (BMI) among those patients with the available information from the database. The total HCRU and all-cause healthcare costs, which both includes inpatient hospitalizations, outpatient services, and prescription fills, was assessed during the 12 months pre-index and post-index period for each index diagnosis of NAFLD/NASH, LC and HCC cohorts. Adjusted total allcause healthcare costs during the 12 months post-index period was also reported using multivariable models. All the variables in this study was descriptively summarized for each NAFLD/NASH, LC, and HCC stage, with the categorical variables stated percentages and counts, and the continuous variables stated as a mean average with standard deviations. $\chi^{2}$ tests used when measuring categorical variables as statistical significance, and the student $t$ tests used when measuring continuous variables as statistical significance. All statistical comparisons of HCRU and cost between pre-index and post-index was performed via paired $t$ test and student $t$ test, respectively. Multivariate analysis used a generalized linear model with gamma distribution and a log link function when measuring associations of the post-index costs and disease severity groups, with all demographic and background comorbidities adjusted. We also analysed the hazard ratios assessed for time-to-event from NAFLD/NASH to LC or HCC diagnosis using the Cox regression model, and the $P$ values were calculated with the stratified log-rank test. All results were considered statistically significant at $p<0.05$, and SAS software version 9.4 (SAS, Carey, NC, US) was used.

\section{Results}

185,012 patients with a diagnostic code for NAFLD or NASH between 1st January 2006 and 31 st July 2018 were eligible for study inclusion. Of these, each NAFLD, LC, and HCC cohort included 123,379, 205, and 96 patients, respectively (Fig. 1).

The mean age of patients across all the severity stages ranged between 46 and 50 years (Table 1 ). Majority of patients were male (70.0-71.7\%). The mean follow-up time were 1,192 \pm 915.2 days, $895 \pm$ 690.0 days and $967 \pm 728.4$ days for the NAFLD/NASH, LC and HCC patients respectfully. Patients who were diagnosed by specialist ranged from $32.0 \%$ with NAFLD/NASH to $64.6 \%$ with HCC. The comorbidity burden was high across all liver disease severity stages, with significantly higher prevalence of comorbid 
conditions in each increasing severity stage compared to NAFLD/NASH. The most prevalent comorbidities included hyperlipidaemia (50.2-61.5\%), diabetes mellitus (40.0-60.4\%), and hypertension (27.9\% to $42.7 \%)$. T2DM was also statistically significantly higher for LC (33.2\%) and HCC (35.4\%) compared to that in NAFLD/NASH (10.6\%), whereas renal impairment was only significantly higher in LC patients $(26.3 \%)$ compared to NAFLD/NASH (18.1\%). All types of infections were similar across all 3 liver diseases severities ranging from $27.4-30.2 \%$. More than two-thirds of the patients across all severity stages including those with NAFLD/NASH had at least 1 comorbidity out of hypertension, hyperlipidaemia, and T2DM. In addition, the proportion of patients with all 3 of these conditions was significantly higher among patients with advanced liver diseases (13.1-20.8\%) compared with NAFLD/NASH (3.9\%) (all $p<0.0001)$. 
Table 1

Demographic and clinical characteristics of NAFLD/NASH, LC, and HCC patients.

\begin{tabular}{|c|c|c|c|}
\hline & NAFLD/NASH & LC & $\mathrm{HCC}$ \\
\hline & $(n=123,379)$ & $(n=205)$ & $(n=96)$ \\
\hline Age in years at index date; (Mean $\pm S D)$ & $46 \pm 11.5$ & $46 \pm 12.2$ & $50 \pm 11.5^{\star}$ \\
\hline \multicolumn{4}{|l|}{ Age group in years at index date, $\mathrm{n}(\%)$} \\
\hline $18-34$ years & $20,531(16.6 \%)$ & 39 (19.0\%) & $9(9.4 \%) \star$ \\
\hline $35-44$ years & $32,084(26.0 \%)$ & $47(22.9 \%)$ & $23(24.0 \%)$ \\
\hline $45-54$ years & $38,225(31.0 \%)$ & 69 (33.7\%) & $25(26.0 \%)$ \\
\hline $55-64$ years & $26,569(21.5 \%)$ & $35(17.1 \%)$ & $30(31.3 \%)$ \\
\hline$\geq 65$ years & $5,969(4.8 \%)$ & $15(7.3 \%)$ & $9(9.4 \%)$ \\
\hline Length of follow-up, days; (Mean \pm SD) & $1,192 \pm 915.2$ & $895 \pm 690.0 * \star \star$ & $967 \pm 728.4^{*}$ \\
\hline Gender: Males (\%) & $86,365(70.0 \%)$ & $147(71.7 \%)$ & $68(70.8 \%)$ \\
\hline \multicolumn{4}{|l|}{ Comorbidity at baseline, $\mathrm{n}(\%)$} \\
\hline Diabetes mellitus & $49,391(40.0 \%)$ & $145(70.7 \%)^{\star}$ & 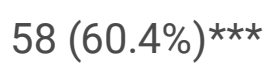 \\
\hline T2DM & $13,016(10.6 \%)$ & $68(33.2 \%)^{\star \star \star}$ & $34(35.4 \%)^{\star \star \star}$ \\
\hline Hyperlipidaemia & $61,882(50.2 \%)$ & $121(59.0 \%)^{\star}$ & $59(61.5 \%)^{*}$ \\
\hline Hypertension & $34,456(27.9 \%)$ & $80(39.0 \%)^{\star \star}$ & $41(42.7 \%)^{\star \star}$ \\
\hline CVD & $14,040(11.4 \%)$ & 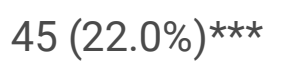 & $24(25.0 \%)^{\star \star \star}$ \\
\hline Renal impairment & $22,283(18.1 \%)$ & $54(26.3 \%) * \star$ & $16(16.7 \%)$ \\
\hline Anaemia & $13,674(11.1 \%)$ & $86(42.0 \%)^{\star \star \star}$ & 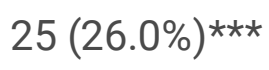 \\
\hline Abdominal pain & $6,685(5.4 \%)$ & $7(3.4 \%)$ & $10(10.4 \%)^{*}$ \\
\hline Infection & $33,834(27.4 \%)$ & $61(29.8 \%)$ & $29(30.2 \%)$ \\
\hline \multicolumn{4}{|c|}{ Combination of "Type 2 diabetes mellitus" or "Hypertension" or "Hyperlipidaemia" } \\
\hline 3 comorbidities, n (\%) & $4,853(3.9 \%)$ & 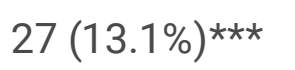 & $20(20.8 \%)^{\star \star \star}$ \\
\hline 2 comorbidities, n (\%) & $24,522(19.9 \%)$ & $53(25.7 \%)$ & $20(20.8 \%)$ \\
\hline
\end{tabular}

\footnotetext{
NAFLD: non-alcoholic fatty liver disease; NASH: non-alcoholic steatohepatitis; LC: liver cirrhosis; HCC: hepatocellular carcinoma; SD: standard deviation; T2DM: type 2 diabetes mellitus; CVD: cardiovascular disease. ${ }^{*} p<0.05$ for comparison of LC or HCC cohort versus NAFLD/NASH; $* * p<0.01$ for comparison of LC or HCC cohort versus NAFLD/NASH; *** $<0.0001$ for comparison of LC or HCC cohort versus NAFLD/NASH.
} 


\begin{tabular}{|lccc|}
\hline & NAFLD/NASH & LC & HCC \\
\hline 1 comorbidity, n (\%) & $45,917(37.2 \%)$ & $82(39.8 \%)$ & $35(36.5 \%)$ \\
\hline No comorbidities, n (\%) & $48,086(39.0 \%)$ & $44(21,4 \%)$ & $21(21.9 \%)$ \\
\hline $\begin{array}{l}\text { NAFLD: non-alcoholic fatty liver disease; NASH: non-alcoholic steatohepatitis; LC: liver cirrhosis; HCC: } \\
\text { hepatocellular carcinoma; SD: standard deviation; T2DM: type 2 diabetes mellitus; CVD: } \\
\text { cardiovascular disease. *p < } 0.05 \text { for comparison of LC or HCC cohort versus NAFLD/NASH; **p < } 0.01 \\
\text { for comparison of LC or HCC cohort versus NAFLD/NASH; **tp < } 0.0001 \text { for comparison of LC or HCC } \\
\text { cohort versus NAFLD/NASH. }\end{array}$ & & \\
\hline
\end{tabular}

Overall, the mean annual number of HCRU across all service categories (inpatient admission, outpatient services, and prescription fills) increased from pre-index to post-index period (all $p<0.0001$ ), (Table 2). The mean annual admissions per patient increased from pre-index to post-index periods (all $p<0.0001$ ). Post-index HCRU across all service categories was significantly higher among patients with advanced liver diseases compared with NAFLD/NASH. The percentage of patients with an inpatient admission was significantly higher among HCC patients versus NAFLD/NASH patients (all $p<0.0001$ ). Mean annual number of admissions per patient were significantly higher among advanced liver diseases compared with NAFLD/NASH (all $p<0.0001$ ). This trend held when comparing mean annual outpatient services and prescription fills. patients, respectively $(p<0.0001)$. 
Table 2

Annual all-cause healthcare resource utilization among NAFLD/NASH, LC, and HCC patients.

\begin{tabular}{|c|c|c|c|c|c|c|}
\hline & \multicolumn{2}{|c|}{ NAFLD/NASH } & \multicolumn{2}{|l|}{ LC } & \multicolumn{2}{|l|}{$\mathrm{HCC}$} \\
\hline & \multicolumn{2}{|c|}{$(n=123,379)$} & \multicolumn{2}{|c|}{$(n=205)$} & \multicolumn{2}{|c|}{$(n=96)$} \\
\hline $\begin{array}{l}\text { Healthcare Resource Utilization } \\
\text { Parameters }\end{array}$ & $\begin{array}{l}\text { Pre- } \\
\text { Index }\end{array}$ & $\begin{array}{l}\text { Post- } \\
\text { Index }\end{array}$ & $\begin{array}{l}\text { Pre- } \\
\text { Index }\end{array}$ & $\begin{array}{l}\text { Post- } \\
\text { Index }\end{array}$ & $\begin{array}{l}\text { Pre- } \\
\text { Index }\end{array}$ & $\begin{array}{l}\text { Post- } \\
\text { Index }\end{array}$ \\
\hline \multicolumn{7}{|l|}{ Inpatient hospitalizations } \\
\hline $\begin{array}{l}\text { Patients with hospitalization [n } \\
(\%)]\end{array}$ & $\begin{array}{l}3,393 \\
(3 \%)\end{array}$ & $\begin{array}{l}8,391 \\
(7 \%)^{*}\end{array}$ & $\begin{array}{l}18 \\
(9 \%)\end{array}$ & $\begin{array}{l}35 \\
(17 \%)\end{array}$ & $6(6 \%)$ & $\begin{array}{l}34 \\
(35 \%)^{*}\end{array}$ \\
\hline $\begin{array}{l}\text { Annual admissions per patient } \\
\text { [mean (SD)] }\end{array}$ & $\begin{array}{l}0.04 \\
(0.27)\end{array}$ & $\begin{array}{l}0.10 \\
(0.42)^{\star}\end{array}$ & $\begin{array}{l}0.17 \\
(0.70)\end{array}$ & $\begin{array}{l}0.31 \\
(0.79)\end{array}$ & 0.10 & $0.68 *$ \\
\hline $\begin{array}{l}\% \text { change from pre-index to } \\
\text { post-index period }\end{array}$ & $150 \%$ & & $82 \%$ & & $580 \%$ & \\
\hline Length of stay [mean (SD)] & $\begin{array}{l}0.34 \\
(2.38)\end{array}$ & $\begin{array}{l}0.83 \\
(3.48)^{*}\end{array}$ & $\begin{array}{l}1.66 \\
(4.85)\end{array}$ & $\begin{array}{l}2.88 \\
(6.12)^{*}\end{array}$ & $\begin{array}{l}0.83 \\
(2.80)\end{array}$ & $\begin{array}{l}6.00 \\
(7.89)^{*}\end{array}$ \\
\hline \multicolumn{7}{|l|}{ Outpatient services } \\
\hline Patients with service [n (\%)] & $\begin{array}{l}99,125 \\
(80 \%)\end{array}$ & $\begin{array}{l}123,329 \\
(99 \%)\end{array}$ & $\begin{array}{l}179 \\
(87 \%)\end{array}$ & $\begin{array}{l}205 \\
(100 \%)^{*}\end{array}$ & $\begin{array}{l}88 \\
(92 \%)\end{array}$ & $\begin{array}{l}96 \\
(100 \%)^{\star}\end{array}$ \\
\hline $\begin{array}{l}\text { Annual services per patient } \\
\text { [mean (SD)] }\end{array}$ & $5.7(8.1)$ & $8.4(8.6)^{\star}$ & $\begin{array}{l}10.8 \\
(14.3)\end{array}$ & $\begin{array}{l}13.2 \\
(14.4)\end{array}$ & $\begin{array}{l}10.4 \\
(11.8)\end{array}$ & $\begin{array}{l}13.1 \\
(9.8)\end{array}$ \\
\hline $\begin{array}{l}\% \text { change from pre-index to } \\
\text { post-index period }\end{array}$ & $46 \%$ & & $22 \%$ & & $26 \%$ & \\
\hline \multicolumn{7}{|l|}{ Prescription fills } \\
\hline Patients with fills [n (\%)] & $\begin{array}{l}76,738 \\
(62 \%)\end{array}$ & $\begin{array}{l}91,642 \\
(74 \%)^{*}\end{array}$ & $\begin{array}{l}151 \\
(74 \%)\end{array}$ & $\begin{array}{l}166 \\
(81 \%)\end{array}$ & $\begin{array}{l}70 \\
(73 \%)\end{array}$ & $\begin{array}{l}79 \\
(83 \%)\end{array}$ \\
\hline $\begin{array}{l}\text { Annual prescriptions per patient } \\
\text { [mean (SD)] }\end{array}$ & $2.4(3.0)$ & $3.1(3.2)^{*}$ & $\begin{array}{l}4.0 \\
(5.0)\end{array}$ & $\begin{array}{l}4.6 \\
(4.8)\end{array}$ & $\begin{array}{l}3.54 \\
(3.3)\end{array}$ & $\begin{array}{l}3.84 \\
(3.0)\end{array}$ \\
\hline $\begin{array}{l}\% \text { change from pre-index to } \\
\text { post-index period }\end{array}$ & \multicolumn{2}{|l|}{$30 \%$} & \multicolumn{2}{|l|}{$17 \%$} & \multicolumn{2}{|l|}{$8 \%$} \\
\hline \multicolumn{7}{|c|}{$\begin{array}{l}\text { NAFLD: non-alcoholic fatty liver disease; NASH: non-alcoholic steatohepatitis; LC: liver cirrhosis; HCC: } \\
\text { hepatocellular carcinoma; SD: standard deviation. }{ }^{*}<<0.05 \text { for comparison of pre-index versus post- } \\
\text { index period. }\end{array}$} \\
\hline
\end{tabular}

The mean total all-cause healthcare annual cost after diagnosis was significantly lower in patients with NAFLD/NASH at $¥ 146,096$ compared to those with more advanced liver diseases at $¥ 399,425$ for LC patients, and $¥ 842,875$ for HCC patients (Fig. 2). Overall, the mean total annual healthcare cost increased at the post-index from pre-index $(p<0.0001)$, with an increase of $75 \%$ in NAFLD/NASH, $50 \%$ in LC, and 
$312 \%$ in HCC patients from pre-index to post-index. Inpatient costs were the largest contributor in both LC and HCC patients, whereas outpatient costs were the major contributor among NAFLD/NASH patients.

After adjusting for potential confounders, the adjusted annual all-cause post-index costs increased with liver disease severity (Table 3). Compared to NAFLD/NASH patients, the increased cost ratio was 1.61 and 3.01 for $L C$ and HCC respectively (all $p<0.0001$ ). Age group cost ratio values increased with age, with the 65 years and over group having the highest cost ratio of $1.16(p<0.0001)$ compared to the 1834 years group. All comorbidities had an increased cost ratio except hyperlipidemia which had a cost ratio of $0.91(p<0.0001)$. Patients with CVD had the highest cost ratio value of $1.77(p<0.0001)$, which was followed by T2DM, abdominal pain, anemia and hypertension, with cost ratios of $1.45,1.43,1.42$, and 1.32 respectfully (all $p<0.0001$ ). Significantly high risk of disease progression within the NAFLD/NASH cohort were those of $\geq 65$ years (HR: 2.65, $p=0.0198$ ) and comorbid T2DM (HR: 1.74, $p=$ 0.0353 ), while those associated with significantly slower disease progression with comorbid hyperlipidemia (HR: 0.65, $p<0.05)$ (Fig. 3). 
Table 3

Total annual all-cause healthcare post- index costs adjusted by demographics and clinical characteristics - Multivariable analysis

\begin{tabular}{|c|c|c|}
\hline Independent Variables & Cost Ratio & $\begin{array}{l}95 \% \mathrm{Cl} \\
\text { (Lower-Upper) }\end{array}$ \\
\hline \multicolumn{3}{|c|}{ Liver disease severity stage } \\
\hline NAFLD/NASH & Reference & - \\
\hline LC & $1.61^{*}$ & $(1.46,1.76)$ \\
\hline $\mathrm{HCC}$ & $3.01^{*}$ & $(2.99,3.04)$ \\
\hline \multicolumn{3}{|l|}{ Age groups } \\
\hline $18-34$ years & Reference & - \\
\hline $35-44$ years & $1.02^{*}$ & $(0.95,1.09)$ \\
\hline $45-54$ years & $1.05^{\star}$ & $(0.98,1.12)$ \\
\hline $55-64$ years & $1.09^{\star}$ & $(1.02,1.16)$ \\
\hline$\geq 65$ years & $1.16^{*}$ & $(1.09,1.24)$ \\
\hline \multicolumn{3}{|l|}{ Comorbidities } \\
\hline Diabetes mellitus & $1.27^{*}$ & $(1.24,1.30)$ \\
\hline T2DM & $1.45^{\star}$ & $(1.43,1.46)$ \\
\hline Hyperlipidaemia & $0.91^{*}$ & $(0.89,0.93)$ \\
\hline Hypertension & $1.32^{*}$ & $(1.30,1.35)$ \\
\hline CVD & $1.77^{\star}$ & $(1.75,1.78)$ \\
\hline Renal impairment & $1.16^{\star}$ & $(1.14,1.18)$ \\
\hline Abdominal pain & $1.43^{*}$ & $(1.41,1.45)$ \\
\hline Anaemia & $1.41^{*}$ & $(1.38,1.44)$ \\
\hline Infections & $1.25^{\star}$ & $(1.22,1.27)$ \\
\hline
\end{tabular}

Cl: confidence interval; NAFLD: non-alcoholic fatty liver disease; NASH: non-alcoholic steatohepatitis; LC: liver cirrhosis; HCC: hepatocellular carcinoma; T2DM: type 2 diabetes mellitus; CVD: cardiovascular disease. ${ }^{*} p<0.05$ for comparison of independent variable versus reference 


\section{Discussion}

High rates of comorbidities were seen in NAFLD/NASH patients, however this increased with those of LC and HCC. $20.8 \%$ and $13.1 \%$ of patients with HCC and LC respectively had all 3 comorbid conditions of T2DM, hypertension, and hyperlipidaemia, compared to only 3.9\% in NAFLD/NASH patients. The high rate of comorbidities reported in this study are consistent with other studies of non-Japanese patients with NAFLD/NASH $[19,23,24]$.

Greater HCRU seemed to have influenced the high costs, which was evident with the increase with LC then further increased with HCC. The increased all-cause annual healthcare cost from NAFLD, to LC, to HCC was $¥ 146,096, ¥ 399,425$, and $¥ 842,875$, respectively, and from the multivariant analysis reported an adjusted specific cost ratio increase of 1.61 and 3.01 for LC and HCC, respectively, compared with patients with NAFLD/NASH. This was similar to NAFLD/NASH and subsequent advanced liver diseases for patients within the US Medicare database, which Wong et al. reported an annual all-cause healthcare cost of $\$ 23,860$ in NAFLD/NASH without advanced liver diseases, with an increase to $\$ 29,078$ and $\$ 97,563$ for compensated cirrhosis and HCC patients respectively [25].

Comorbidities are common in NAFLD/NASH patients and associated with increased utilization and cost estimates [26]. Our multivariate analysis confirmed that CVD was the most significant contributor, followed by T2DM, towards post-index cost regardless of advanced liver diseases severity. This observation is in concert with those by Sayiner et al. which reported CVD as an independent predictor of costs in the US [19], and Younossi et al. reported the strong association of T2DM with high costs among NAFLD/NASH patients [27]. An unexpected finding was the association of hyperlipidaemia with reduced costs and lower rate of disease progression, which may be due to the exposure statins for hyperlipidaemia treatment resulting in reduced risk of LC and HCC progression $[28,29]$.

\section{Limitations}

The lack of biopsy data in the JMDC database meant we depended on diagnosis codes to define the NASH patients. Also, as the JMDC database includes a primarily working and employed population, the older population is likely underrepresented. However, this study provides real-world novel proof of NAFLD and NASH adult patients in Japan and highlights need for early diagnosis and treatment to improve the healthcare economic burden. Future studies to incorporate the treatment duration, effect on disease progression and price of currently developing NAFLD/NASH targeted pharmacological therapies once approved in Japan.

\section{Conclusions}

The results from this study suggest that NAFLD/NASH patients with advanced liver diseases have increased comorbidity burden, high HCRU, and healthcare costs. This further highlights the importance and need of early identification and effective management in order to minimize the clinical and economic burden for NAFLD/NASH patients in Japan. 


\section{Declarations}

Conflict of interest: $\mathrm{K} \mathrm{H}$ is an employee of Gilead Sciences Inc., but the views of the author in this paper do not reflect the views of the company. A A has no conflicts of interest to disclose.

Author contribution: $\mathrm{K} \mathrm{H}$ and A A met the International Committee of Medical Journal Editors criteria for good authorship practice, and contributed to the study design, analysis and the interpretation of data. $\mathrm{K}$ $\mathrm{H}$ and $\mathrm{A} A$ have full responsibility for integrity of this manuscript.

Ethical approval: As this study used only deidentified patient records with no active enrolment, follow up, or direct data collection from individuals, an Institutional Review Board review or approval was not required. Informed consent was also not required.

Funding: No funding was received for this study

Data availability: The data provided by the JMDC is not publicly available and the data license agreement with JMDC does not permit the data sharing with external people. Interested readers can request the data from the JMDC directly.

\section{References}

1. Younossi Z, Anstee QM, Marietti M, Hardy T, Henry L, Eslam M, et al. Global burden of NAFLD and NASH: trends, predictions, risk factors and prevention. Nat Rev Gastroenterol Hepatol 2018;15(1):1120

2. Neuschwander-Tetri BA, Caldwell SH. Nonalcoholic steatohepatitis: summary of an AASLD Single Topic Conference. Hepatology 2003;37(5):1202-1219

3. Younossi ZM, Koenig AB, Abdelatif D, Fazel Y, Henry L, Wymer M. Global epidemiology of nonalcoholic fatty liver disease-Meta-analytic assessment of prevalence, incidence, and outcomes. Hepatology 2016;64(1):73-84

4. Le MH, Devaki P, Ha NB, Jun DW, Te HS, Cheung RC, et al. Prevalence of non-alcoholic fatty liver disease and risk factors for advanced fibrosis and mortality in the United States. PLoS One 2017;12(3):e0173499

5. Younossi ZM. Non-alcoholic fatty liver disease - A global public health perspective. J Hepatol 2019;70(3):531-544

6. Eguchi Y, Hyogo H, Ono M, Mizuta T, Ono N, Fujimoto K, et al. Prevalence and associated metabolic factors of nonalcoholic fatty liver disease in the general population from 2009 to 2010 in Japan: a multicenter large retrospective study. J Gastroenterol 2012;47(5):586-595

7. Nishioji K, Sumida Y, Kamaguchi M, Mochizuki N, Kobayashi M, Nishimura T, et al. Prevalence of and risk factors for non-alcoholic fatty liver disease in a non-obese Japanese population, 2011-2012. J Gastroenterol 2015;50(1):95-108 
8. Anstee QM, Targher G, Day CP. Progression of NAFLD to diabetes mellitus, cardiovascular disease or cirrhosis. Nat Rev Gastroenterol Hepatol 2013;10(6):330-344

9. Ekstedt M, Hagstrom H, Nasr P, Fredrikson M, Stal P, Kechagias S, et al. Fibrosis stage is the strongest predictor for disease-specific mortality in NAFLD after up to 33 years of follow-up. Hepatology 2015;61(5):1547-1554.

10. Anstee QM, Reeves HL, Kotsiliti E, Govaere O, Heikenwalder M. From NASH to HCC: current concepts and future challenges. Nat Rev Gastroenterol Hepatol 2019;16(7):411-428

11. Ballestri S, Zona S, Targher G, Romagnoli D, Baldelli E, Nascimbeni F. Nonalcoholic fatty liver disease is associated with an almost twofold increased risk of incident type 2 diabetes and metabolic syndrome. Evidence from a systematic review and meta-analysis. J Gastroenterol Hepatol 2016;31(5):936-944

12. Ryoo JH, Suh YJ, Shin HC, Cho YK, Choi JM, Park SK. Clinical association between non-alcoholic fatty liver disease and the development of hypertension. J Gastroenterol Hepatol 2014;29(11):19261931

13. Sung KC, Wild SH, Byrne CD. Development of new fatty liver, or resolution of existing fatty liver, over five years of follow-up, and risk of incident hypertension. J Hepatol 2014;60(5):1040-1045

14. Chalasani N, Younossi Z, Lavine JE, Charlton M, Cusi K, Rinella M. The diagnosis and management of nonalcoholic fatty liver disease: Practice guidance from the American Association for the Study of Liver Diseases. Hepatology 2018;67(1):328-357

15. Schuppan D, Schattenberg JM. Non-alcoholic steatohepatitis: pathogenesis and novel therapeutic approaches. J Gastroenterol Hepatol 2013;28:68-76

16. Watanabe S, Hashimoto E, Ikejima K, Uto H, Ono M, Sumida Y. Evidence-based clinical practice guidelines for nonalcoholic fatty liver disease/nonalcoholic steatohepatitis. J Gastroenterol 2015;50(4):364-377

17. Younossi ZM, Blissett D, Blissett R, Henry L, Stepanova M, Younossi Y. The economic and clinical burden of nonalcoholic fatty liver disease in the United States and Europe. Hepatology 2016;64(5):1577-1586

18. Younossi ZM, Zheng L, Stepanova M, Henry L, Venkatesan C, Mishra A. Trends in outpatient resource utilizations and outcomes for Medicare beneficiaries with nonalcoholic fatty liver disease. J Clin Gastroenterol 2015;49(3):222-227

19. Sayiner M, Otgonsuren M, Cable R, Younossi I, Afendy M, Golabi P. Variables Associated With Inpatient and Outpatient Resource Utilization Among Medicare Beneficiaries With Nonalcoholic Fatty Liver Disease With or Without Cirrhosis. J Clin Gastroenterol 2017;51(3):254-260

20. Baumeister SE, Volzke H, Marschall P, John U, Schmidt CO, Flessa S, et al. Impact of fatty liver disease on health care utilization and costs in a general population: a 5-year observation. Gastroenterology 2008;134(1):85-94

21. Japan Medical Data Center. http://www.jmdc.co.jp/ 
22. Kimura S, Sato T, Ikeda S, Noda M, Nakayama T. Development of a database of health insurance claims: standardization of disease classifications and anonymous record linkage. J Epidemiol 2010;20(5):413-419

23. Adams LA, Anstee QM, Tilg H, Targher G. Non-alcoholic fatty liver disease and its relationship with cardiovascular disease and other extrahepatic diseases. Gut 2017;66(6):1138-1153

24. Ahmed A, Wong RJ, Harrison SA. Nonalcoholic Fatty Liver Disease Review: Diagnosis, Treatment, and Outcomes. Clin Gastroenterol Hepatol 2015;13(12):2062-2070

25. Wong RJ, Kachru N, Martinez DJ, Moynihan M, Ozbay AB, Gordon SC. Real-world Comorbidity Burden, Health Care Utilization, and Costs of Nonalcoholic Steatohepatitis Patients With Advanced Liver Diseases. J Clin Gastroenterol 2020 doi.10.1097/MCG.0000000000001409

26. Gordon SC, Fraysse J, Li S, Ozbay AB, Wong RJ. Disease Severity Is Associated With Higher Healthcare Utilization in Nonalcoholic Steatohepatitis Medicare Patients. Am J Gastroenterol 2020;115(4):562-574

27. Younossi ZM, Tampi RP, Racila A, Qiu Y, Burns L, Younossi I, et al. Economic and Clinical Burden of Nonalcoholic Steatohepatitis in Patients With Type 2 Diabetes in the U.S.. Diabetes Care 2020;43(2):283-289

28. Kaplan DE, Serper MA, Mehta R, Fox R, John B, Aytaman A, et al. Effects of Hypercholesterolemia and Statin Exposure on Survival in a Large National Cohort of Patients with Cirrhosis. Gastroenterology 2019;156(6):1693-1706

29. Singh S, Singh PP, Singh AG, Murad MH, Sanchez W. Statins are associated with a reduced risk of hepatocellular cancer: a systematic review and meta-analysis. Gastroenterology 2013;144(2):323332

\section{Tables}

Table 1. Demographic and clinical characteristics of NAFLD/NASH, LC, and HCC patients. 


\begin{tabular}{|c|c|c|c|}
\hline & NAFLD/NASH & LC & $\mathrm{HCC}$ \\
\hline & $(n=123,379)$ & $(n=205)$ & $(n=96)$ \\
\hline Age in years at index date; (Mean \pm SD) & $46 \pm 11.5$ & $46 \pm 12.2$ & $50 \pm 11.5^{\star}$ \\
\hline \multicolumn{4}{|l|}{ Age group in years at index date, $\mathrm{n}(\%)$} \\
\hline $18-34$ years & $20,531(16.6 \%)$ & $39(19.0 \%)$ & $9(9.4 \%) *$ \\
\hline $35-44$ years & $32,084(26.0 \%)$ & $47(22.9 \%)$ & $23(24.0 \%)$ \\
\hline $45-54$ years & $38,225(31.0 \%)$ & $69(33.7 \%)$ & $25(26.0 \%)$ \\
\hline $55-64$ years & $26,569(21.5 \%)$ & $35(17.1 \%)$ & $30(31.3 \%)$ \\
\hline$\geq 65$ years & $5,969(4.8 \%)$ & $15(7.3 \%)$ & $9(9.4 \%)$ \\
\hline Length of follow-up, days; (Mean \pm SD) & $1,192 \pm 915.2$ & $895 \pm 690.0 \star \star \star$ & $967 \pm 728.4^{*}$ \\
\hline Gender: Males (\%) & $86,365(70.0 \%)$ & $147(71.7 \%)$ & $68(70.8 \%)$ \\
\hline \multicolumn{4}{|l|}{ Comorbidity at baseline, $\mathrm{n}(\%)$} \\
\hline Diabetes mellitus & $49,391(40.0 \%)$ & $145(70.7 \%)^{\star}$ & $58(60.4 \%)^{\star \star \star}$ \\
\hline T2DM & $13,016(10.6 \%)$ & $68(33.2 \%)^{\star \star \star}$ & $34(35.4 \%)^{\star \star \star}$ \\
\hline Hyperlipidaemia & $61,882(50.2 \%)$ & $121(59.0 \%)^{*}$ & $59(61.5 \%)^{\star}$ \\
\hline Hypertension & $34,456(27.9 \%)$ & $80(39.0 \%)^{\star \star}$ & $41(42.7 \%)^{\star \star}$ \\
\hline CVD & $14,040(11.4 \%)$ & 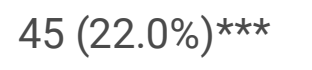 & 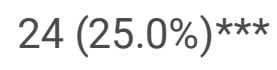 \\
\hline Renal impairment & $22,283(18.1 \%)$ & $54(26.3 \%) \star \star ~$ & $16(16.7 \%)$ \\
\hline Anaemia & $13,674(11.1 \%)$ & 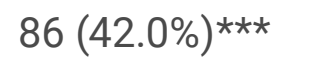 & 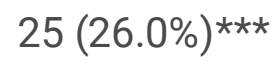 \\
\hline Abdominal pain & $6,685(5.4 \%)$ & $7(3.4 \%)$ & $10(10.4 \%)^{\star}$ \\
\hline Infection & $33,834(27.4 \%)$ & $61(29.8 \%)$ & $29(30.2 \%)$ \\
\hline \multicolumn{4}{|c|}{ Combination of "Type 2 diabetes mellitus" or "Hypertension" or "Hyperlipidaemia" } \\
\hline 3 comorbidities, n (\%) & $4,853(3.9 \%)$ & 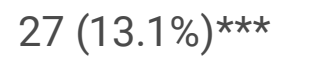 & $20(20.8 \%)^{\star \star \star}$ \\
\hline 2 comorbidities, $\mathrm{n}(\%)$ & $24,522(19.9 \%)$ & $53(25.7 \%)$ & $20(20.8 \%)$ \\
\hline 1 comorbidity, n (\%) & $45,917(37.2 \%)$ & $82(39.8 \%)$ & 35 (36.5\%) \\
\hline No comorbidities, n (\%) & $48,086(39.0 \%)$ & $44(21,4 \%)$ & $21(21.9 \%)$ \\
\hline
\end{tabular}

NAFLD: non-alcoholic fatty liver disease; NASH: non-alcoholic steatohepatitis; LC: liver cirrhosis; HCC: hepatocellular carcinoma; SD: standard deviation; T2DM: type 2 diabetes mellitus; CVD: cardiovascular disease. ${ }^{\star} p<0.05$ for comparison of LC or HCC cohort versus NAFLD/NASH; ${ }^{\star \star} p<0.01$ for comparison of 
LC or HCC cohort versus NAFLD/NASH; ${ }^{\star \star \star} p<0.0001$ for comparison of LC or HCC cohort versus NAFLD/NASH.

Table 2. Annual all-cause healthcare resource utilization among NAFLD/NASH, LC, and HCC patients.

\begin{tabular}{|c|c|c|c|c|c|c|}
\hline & NAFLD/N & & LC & & $\mathrm{HCC}$ & \\
\hline & $(n=123,3$ & & $(\mathrm{n}=20$ & & $(n=96)$ & \\
\hline $\begin{array}{l}\text { Healthcare Resource Utilization } \\
\text { Parameters }\end{array}$ & $\begin{array}{l}\text { Pre- } \\
\text { Index }\end{array}$ & $\begin{array}{l}\text { Post- } \\
\text { Index }\end{array}$ & $\begin{array}{l}\text { Pre- } \\
\text { Index }\end{array}$ & $\begin{array}{l}\text { Post- } \\
\text { Index }\end{array}$ & $\begin{array}{l}\text { Pre- } \\
\text { Index }\end{array}$ & $\begin{array}{l}\text { Post- } \\
\text { Index }\end{array}$ \\
\hline Inpatient hospitalizations & & & & & & \\
\hline $\begin{array}{l}\text { Patients with hospitalization [n } \\
(\%)]\end{array}$ & $\begin{array}{l}3,393 \\
(3 \%)\end{array}$ & $\begin{array}{l}8,391 \\
(7 \%)^{*}\end{array}$ & $\begin{array}{l}18 \\
(9 \%)\end{array}$ & $\begin{array}{l}35 \\
(17 \%)\end{array}$ & $6(6 \%)$ & $\begin{array}{l}34 \\
(35 \%)^{\star}\end{array}$ \\
\hline $\begin{array}{l}\text { Annual admissions per patient } \\
\text { [mean (SD)] }\end{array}$ & $\begin{array}{l}0.04 \\
(0.27)\end{array}$ & $\begin{array}{l}0.10 \\
(0.42) *\end{array}$ & $\begin{array}{l}0.17 \\
(0.70)\end{array}$ & $\begin{array}{l}0.31 \\
(0.79)\end{array}$ & 0.10 & $0.68^{*}$ \\
\hline $\begin{array}{l}\% \text { change from pre-index to } \\
\text { post-index period }\end{array}$ & $150 \%$ & & $82 \%$ & & $580 \%$ & \\
\hline Length of stay [mean (SD)] & $\begin{array}{l}0.34 \\
(2.38)\end{array}$ & $\begin{array}{l}0.83 \\
(3.48)^{\star}\end{array}$ & $\begin{array}{l}1.66 \\
(4.85)\end{array}$ & $\begin{array}{l}2.88 \\
(6.12) *\end{array}$ & $\begin{array}{l}0.83 \\
(2.80)\end{array}$ & $\begin{array}{l}6.00 \\
(7.89)^{\star}\end{array}$ \\
\hline Outpatient services & & & & & & \\
\hline Patients with service [n (\%)] & $\begin{array}{l}99,125 \\
(80 \%)\end{array}$ & $\begin{array}{l}123,329 \\
(99 \%)\end{array}$ & $\begin{array}{l}179 \\
(87 \%)\end{array}$ & $\begin{array}{l}205 \\
(100 \%)^{*}\end{array}$ & $\begin{array}{l}88 \\
(92 \%)\end{array}$ & $\begin{array}{l}96 \\
(100 \%)^{*}\end{array}$ \\
\hline $\begin{array}{l}\text { Annual services per patient } \\
\text { [mean (SD)] }\end{array}$ & $5.7(8.1)$ & $8.4(8.6)^{*}$ & $\begin{array}{l}10.8 \\
(14.3)\end{array}$ & $\begin{array}{l}13.2 \\
(14.4)\end{array}$ & $\begin{array}{l}10.4 \\
(11.8)\end{array}$ & $\begin{array}{l}13.1 \\
(9.8)\end{array}$ \\
\hline $\begin{array}{l}\% \text { change from pre-index to } \\
\text { post-index period }\end{array}$ & $46 \%$ & & $22 \%$ & & $26 \%$ & \\
\hline Prescription fills & & & & & & \\
\hline Patients with fills [n (\%)] & $\begin{array}{l}76,738 \\
(62 \%)\end{array}$ & $\begin{array}{l}91,642 \\
(74 \%)^{*}\end{array}$ & $\begin{array}{l}151 \\
(74 \%)\end{array}$ & $\begin{array}{l}166 \\
(81 \%)\end{array}$ & $\begin{array}{l}70 \\
(73 \%)\end{array}$ & $\begin{array}{l}79 \\
(83 \%)\end{array}$ \\
\hline $\begin{array}{l}\text { Annual prescriptions per patient } \\
\text { [mean (SD)] }\end{array}$ & $2.4(3.0)$ & $3.1(3.2)^{\star}$ & $\begin{array}{l}4.0 \\
(5.0)\end{array}$ & $4.6(4.8)$ & $\begin{array}{l}3.54 \\
(3.3)\end{array}$ & $\begin{array}{l}3.84 \\
(3.0)\end{array}$ \\
\hline $\begin{array}{l}\% \text { change from pre-index to } \\
\text { post-index period }\end{array}$ & $30 \%$ & & $17 \%$ & & $8 \%$ & \\
\hline
\end{tabular}


NAFLD: non-alcoholic fatty liver disease; NASH: non-alcoholic steatohepatitis; LC: liver cirrhosis; HCC: hepatocellular carcinoma; SD: standard deviation. ${ }^{*} P<0.05$ for comparison of pre-index versus postindex period.

Table 3. Total annual all-cause healthcare post- index costs adjusted by demographics and clinical characteristics - Multivariable analysis 


\begin{tabular}{|c|c|c|}
\hline Independent Variables & Cost Ratio & $\begin{array}{l}95 \% \mathrm{Cl} \\
\text { (Lower-Upper) }\end{array}$ \\
\hline \multicolumn{3}{|c|}{ Liver disease severity stage } \\
\hline NAFLD/NASH & Reference & - \\
\hline LC & $1.61^{\star}$ & $(1.46,1.76)$ \\
\hline $\mathrm{HCC}$ & $3.01^{*}$ & $(2.99,3.04)$ \\
\hline \multicolumn{3}{|l|}{ Age groups } \\
\hline $18-34$ years & Reference & - \\
\hline $35-44$ years & $1.02^{*}$ & $(0.95,1.09)$ \\
\hline $45-54$ years & $1.05^{*}$ & $(0.98,1.12)$ \\
\hline $55-64$ years & $1.09^{*}$ & $(1.02,1.16)$ \\
\hline$\geq 65$ years & $1.16^{*}$ & $(1.09,1.24)$ \\
\hline \multicolumn{3}{|l|}{ Comorbidities } \\
\hline Diabetes mellitus & $1.27^{\star}$ & $(1.24,1.30)$ \\
\hline T2DM & $1.45^{*}$ & $(1.43,1.46)$ \\
\hline Hyperlipidaemia & $0.91^{*}$ & $(0.89,0.93)$ \\
\hline Hypertension & $1.32^{*}$ & $(1.30,1.35)$ \\
\hline CVD & $1.77^{\star}$ & $(1.75,1.78)$ \\
\hline Renal impairment & $1.16^{*}$ & $(1.14,1.18)$ \\
\hline Abdominal pain & $1.43^{*}$ & $(1.41,1.45)$ \\
\hline Anaemia & $1.41^{*}$ & $(1.38,1.44)$ \\
\hline Infections & $1.25^{\star}$ & $(1.22,1.27)$ \\
\hline
\end{tabular}

Cl: confidence interval; NAFLD: non-alcoholic fatty liver disease; NASH: non-alcoholic steatohepatitis; LC: liver cirrhosis; HCC: hepatocellular carcinoma; T2DM: type 2 diabetes mellitus; CVD: cardiovascular disease. ${ }^{*} p<0.05$ for comparison of independent variable versus reference 
Figures

Patients with a diagnosis code for NAFLD/NASH from 1 January 2006 to 31 July 2018

$$
n=185,012
$$

Patients who were 18 years or over at NAFLD/NASH diagnosis date

$$
\mathrm{n}=182,725
$$

Patients with 12 months pre-index and post-index on NAFLD/NASH diagnosis date

$$
\mathrm{n}=137,455
$$

Patients meeting the selection criteria (NAFLD/NASH cohort)

$$
\mathrm{n}=123,379
$$

LC cohort

$\mathrm{n}=\mathbf{2 0 5}$

HCC cohort

$\mathrm{n}=96$

Figure 1

Patient selection flowchart for identification of the study cohorts. NAFLD: non-alcoholic fatty liver disease; NASH: non-alcoholic steatohepatitis; LC: liver cirrhosis; HCC: hepatocellular carcinoma

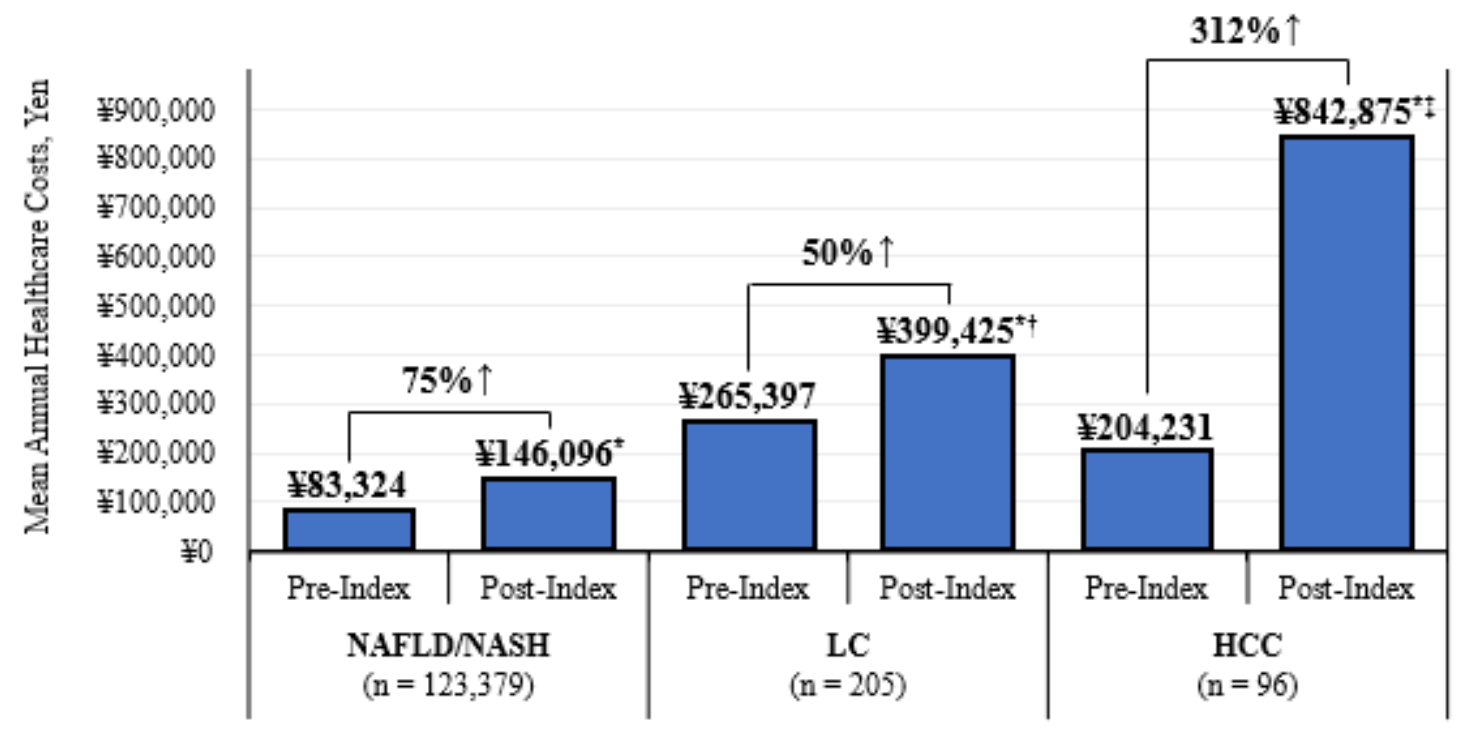

Figure 2 
Annual all-cause health care costs among NAFLD/NASH, LC, and HCC patients. NAFLD: non-alcoholic fatty liver disease; NASH: non-alcoholic steatohepatitis; LC: liver cirrhosis; HCC: hepatocellular carcinoma. ${ }^{*} p<0.05$ for comparison of pre-index versus post-index period for each disease state; $\uparrow p<0.05$ for comparison of LC (post-index) versus NAFLD/NASH (post-index); $\neq p<0.05$ for comparison of HCC (postindex) versus LC (post-index).

\section{Parameter}

Age

Reference (vs 18-34 years)

$35-44$ years

$45-54$ years

55-64 years

$\geq 65$ years

Gender

Male

Comorbidity

Cardiovascular Disease

Type 2 diabetes mellitus

Abdominal pain

Anemia

Hypertension

Infections

Renal Impairment

Hyperlipidemia
10
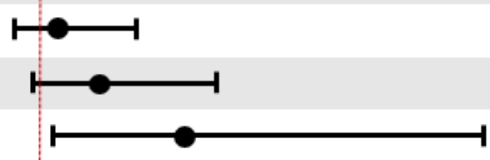

$\mapsto$

$1.21(0.71-2.06)$

$1.74(1.04-2.91)$

$0.51(0.13-2.07)$

$1.07(0.61-1.89)$

$0.67(0.43-1.04)$

$1.03(0.70-1.52)$

$1.09(0.69-1.74)$

$0.64(0.45-0.92)$
0.1009

0.4195

0.0839

0.0204

0.3789

0.4914

0.0355

0.3469

0.8081

0.0762

0.8814

0.7043

0.0170

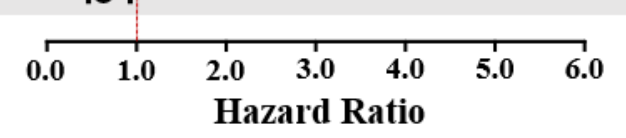

\section{Figure 3}

Stratified hazard ratio comparison of NAFLD/NASH time-to-event of disease progression. Cl: confidence interval.

\section{Supplementary Files}

This is a list of supplementary files associated with this preprint. Click to download.

- SupplementaryMaterials.docx 